DEMOGRAPHIC RESEARCH

VOLUME 39, ARTICLE 11, PAGES 337-364 PUBLISHED 29 AUGUST 2018

https://www.demographic-research.org/Volumes/Vol39/11/

DOI: 10.4054/DemRes.2018.39.11

Research Article

Using census data to measure maternal mortality: A review of recent experience

Kenneth Hill

Peter Johnson

Kavita Singh

Anthony Amuzu-Pharin

Yagya Kharki

(C) 2018 Kenneth Hill et al.

This open-access work is published under the terms of the Creative Commons Attribution 3.0 Germany (CC BY 3.0 DE), which permits use, reproduction, and distribution in any medium, provided the original author(s) and source are given credit.

See https://creativecommons.org/licenses/by/3.0/de/legalcode. 


\section{Contents}

$1 \quad$ Background 338

2 Data 341

3 Methods 343

3.1 Evaluating numbers of births 343

3.2 Evaluating numbers of adult female deaths 344

3.3 Evaluating the proportion pregnancy-related of adult female deaths 345

$\begin{array}{lll}3.4 & \text { Data adjustment } & 345\end{array}$

$4 \quad$ Results 346

4.1 Data evaluation 346

4.2 Comparing adjusted estimates with those from other sources 352

5 Discussion 353

$\begin{array}{lll}6 & \text { Conclusion } & 358\end{array}$

$\begin{array}{llr}7 & \text { Funding statement } & 359\end{array}$

8 Acknowledgements 359

References 360 


\title{
Using census data to measure maternal mortality: A review of recent experience
}

\author{
Kenneth Hill ${ }^{1}$ \\ Peter Johnson ${ }^{2}$ \\ Kavita Singh ${ }^{3}$ \\ Anthony Amuzu-Pharin ${ }^{4}$ \\ Yagya Kharki ${ }^{5}$
}

\begin{abstract}
BACKGROUND

The Sustainable Development Goals adopted by the United Nations General Assembly in 2015 (United Nations 2015) set national targets for reducing maternal mortality, putting pressure on governments of countries lacking comprehensive statistical systems to find other ways to measure it. One approach tested since the 1990s has been to collect necessary data through national population censuses.
\end{abstract}

\section{OBJECTIVE}

This paper reviews maternal mortality data from the 2010 round of censuses for several countries to determine whether the census is useful for monitoring maternal mortality.

\section{METHODS}

Data on births, deaths, and pregnancy-related deaths from two censuses for 10 countries was evaluated using standard methods; adjustments were applied to the reported numbers if so indicated.

\section{RESULTS}

In general, the censuses underreported births moderately and underreported deaths by larger amounts; except in one case, proportions of pregnancy-related deaths appeared plausible. Adjusted estimates of the pregnancy-related mortality ratio (PRMR) were generally higher than estimates from Demographic and Health Survey sibling data or estimates of maternal mortality developed by cross-national studies.

\footnotetext{
${ }^{1}$ Independent researcher, USA. Email: kenneth_hill_1@yahoo.com.

${ }^{2}$ Bureau of the Census, Suitland, USA.

${ }^{3}$ University of North Carolina at Chapel Hill, USA.

${ }^{4}$ Ghana Statistical Service, Accra, Ghana.

${ }^{5}$ National Planning Commission, Kathmandu, Nepal.
} 


\section{CONCLUSIONS}

Analysis of recent data confirms results of earlier assessments: Census data provides imperfect but still valuable information on maternal mortality. Data requires careful assessment and often adjustment, resulting in estimates with large uncertainty.

\section{CONTRIBUTION}

This paper provides additional evidence as to whether maternal mortality can usefully be measured by population censuses in countries lacking civil registration data.

\section{Background}

The first target of Goal Three of the Sustainable Development Goals adopted by the United Nations General Assembly in 2015 (United Nations 2015) is to reduce the global maternal mortality ratio (MMR) to less than 70 maternal deaths per 100,000 live births by the year 2030. This new target continued a long history of international agreements to improve global maternal health, from the 1987 Safe Motherhood Conference to the United Nations Millennium Development Goals (MDG) in 2000. Each agreement sets targets in terms of a specified reduction in the MMR, putting pressure on governments of countries lacking comprehensive civil registration and vital statistics (CRVS) systems to put alternative systems in place to measure maternal mortality; see Hill (2013) for an overview of data needs for measuring maternal mortality. However, in 2015, 12 countries included in a global analysis by UN agencies did not have nationally representative data (WHO 2015).

A maternal death is defined by the International Classification of Diseases Tenth Revision (ICD-10; WHO 1993) as "the death of a woman while pregnant or within 42 days of termination of pregnancy, irrespective of the duration or site of the pregnancy, from any cause related to or aggravated by the pregnancy or its management but not from accidental or incidental causes." The MMR for a period is defined as maternal deaths in that period divided by births in that period, conventionally multiplied by a scaling factor of 100,000. A parallel concept is a pregnancy-related death, defined as any death of a woman while pregnant or within 42 days of termination of pregnancy, regardless of cause; maternal deaths are thus a subset of pregnancy-related deaths. A parallel measure is the pregnancy-related mortality ratio (PRMR), which looks at pregnancy-related deaths per 100,000 live births.

The availability of, and interest in, maternal mortality data has increased over the past decade. International agencies established the Maternal Mortality Estimation Interagency Group (MMEIG) to compile data and publish global, regional, and country estimates on a regular basis (WHO 2015). The ideal source of data for measuring 
maternal mortality is a fully functional CRVS system with accurate attribution of cause of death. However, many low- and middle-income countries lack such systems, so other sources of data have had to be used. The most widely available additional data source is the sibling histories collected by the Demographic and Health Surveys and Multiple Indicator Cluster Surveys programs (Rutenberg and Sullivan 1991). Sibling histories ask respondents about all their brothers and sisters. For siblings that are still alive the only information collected is current age; for siblings that have died, information is recorded on how many years' ago the sibling died and at what age; for deaths of females at ages 13 to 49 , three further questions are asked concerning the timing of death relative to pregnancy or childbirth. These questions identify pregnancy-related deaths rather than maternal mortality itself. The focus on pregnancy-related rather than maternal deaths simplifies data collection, since all that is required is information on the timing of death relative to pregnancy rather than an often problematic attribution of cause of death.

Sibling histories thus estimate PRMRs (although this is not generally made clear in published reports). Estimates based on sibling histories also have large sampling errors: Samples are small, and the events of interest are rare, with the result that potential sampling errors are large. Kish (2003) suggests a minimum acceptable precision for the coefficient of variation (standard error relative to the mean) of $10 \%$; very few surveys provide a national estimate of PRMR for the seven year period before the survey with a coefficient of variation below that threshold. Estimates may also be affected by systematic errors (Ahmed et al. 2014; Masquelier 2013; Hill 2013).

National population censuses have also been used to arrive at estimates of maternal or pregnancy-related mortality. The origin of the idea of using a census as a way of collecting information about maternal mortality is not clear, though the inclusion of questions on deaths by age and sex in the previous 12 months in population censuses has a long history. It was mostly limited to African countries in the 1970 ( 8 countries) and 1980 (22 countries) census rounds but expanded to Asian and Latin American countries in the 1990 (37 countries overall), 2000 (53 countries), and 2010 (72 countries) rounds. A small number of countries in the 1990 census round experimented with adding questions about the timing of deaths of women of reproductive age relative to pregnancy, thus providing a basis for identifying pregnancy-related deaths, and the number expanded dramatically in the 2000 round (17 countries) and 2010 round (61 countries). The experience of the five countries that collected the necessary data in the 1990 round is reviewed by Stanton et al. (2001), for African countries in the 2000 round by Hill et al. (2007), and for Latin American countries by Hill et al. (2009). Guidelines for potential users of such information were prepared (Hill, Stanton, and Gupta 2001); the guidelines were revised about a decade later, drawing on additional experience and incorporating a broader range of country examples (WHO 2013). As with sibling 
histories, the measures generated are of pregnancy-related mortality, so the only data necessary is numbers of pregnancy-related deaths and of births.

The census was seen as having several advantages as a vehicle for collecting data on pregnancy-related mortality relative to sibling histories: Its size would reduce random errors and permit subnational analyses; its marginal cost would be small if the census was being taken anyway; the information on household deaths would additionally permit monitoring of mortality at all ages; and by collecting information about household deaths, it would be possible to follow up the census with a verbal autopsy (WHO 2007) applied to households with identified deaths to refine the estimation of maternal, as opposed to pregnancy-related, mortality, an approach implemented in the 2007 census of Mozambique (Mozambique National Institute of Statistics 2012).

In response to the increased need for maternal mortality data after the Millennium Summit in 2000, the Second Revision of the United Nations Principles and Recommendations for Population and Housing Censuses (PRPHC) included questions on household deaths in the 12 months before the census (or other clearly defined recent reference period) as a core topic and went on to note (paragraph 2.196) that countries "may wish" to add two additional questions about cause of death: whether the death was due to accident, violence, homicide, or suicide; and, if the deceased was a woman aged 15 to 49, whether the woman was pregnant, in childbirth, or within six weeks of the end of pregnancy when she died (United Nations 2007). In practice, the information on the timing of death relative to childbirth is sometimes collected by one single question and other times by three separate questions (while pregnant, during childbirth, or postpartum). The PRPHC adds (paragraph 2.197) that the information must be "interpreted with caution after careful evaluation and often adjustment."

The inclusion of the language in paragraph 2.196 in the revised PRPHC led to increased use of the questions in the 2010 round of censuses. A workshop in Addis Ababa in 2014 reviewed the experience of six African countries, and a Bangkok workshop in 2015 reviewed the experience of seven Asian countries. The purpose of this paper is to present a systematic assessment of data collected in the 2010 census round based on the countries represented at the two workshops. It adds recent experience to a substantial literature evaluating the performance of census-based questions on pregnancy-related mortality (Hill et al. 2007; Hill et al. 2009; Hakkert 2011; Hill and Stanton 2011; Dorrington and Bradshaw 2011).

A key advantage cited for using the census as a basis for estimating pregnancyrelated mortality is size and thus the ability to obtain subnational estimates. Several authors have reviewed the performance of the approach, including Queiroz (2011), Banda, Fylkesnes, and Sandøy (2015), and Banda, Sandøy, and Fylkesnes (2015). This review however will focus on national estimates. 
The ultimate objective of the review is to inform the design and implementation of censuses for the 2020 round. The paper does not aim to produce new estimates of maternal mortality for the countries included, though as part of the evaluation exercise we compare census-based estimates to those derived from other sources, especially sisterhood questions, and those developed by the MMEIG and Global Burden of Disease exercises.

As a result of problems with data access or permissions, it has only been possible to use data in this review from 8 (Cambodia, Ethiopia, Ghana, Liberia, Malawi, Nepal, Vietnam, and Zambia) of the 13 countries that participated in the workshops. In order to expand the number of countries included, we have added data for two additional countries (Burkina Faso and Mozambique) for which appropriate data is available from the Integrated Public Use Microdata Series (Minnesota Population Center 2015).

\section{Data}

Table 1 summarizes the census data available for the countries included in the analysis. The relevant census questionnaires relating to household deaths are reproduced in the web appendix. The precise way in which data on household deaths was collected varies from country to country. In Ethiopia, Mozambique, and Vietnam data on deaths was only collected for the sample of households that received a long-form questionnaire. In Burkina Faso, Ethiopia, Liberia, Mozambique, and Nepal, the only information collected about each reported death in addition to age and sex was for deaths of women of reproductive age as to the timing of death relative to pregnancy. In Cambodia, Vietnam, and Zambia, the questions on the timing of death relative to pregnancy were preceded by a question for all deaths about the cause of death (with a skip in Vietnam such that if the cause was reported as accidental, the questions on timing relative to pregnancy were not asked); in Ghana and Malawi they were preceded by questions as to whether the death was due to accident, violence, or suicide. 
Hill et al:: Using census data to measure maternal mortality: A review of recent experience

Table 1: Summary information about census data used

\begin{tabular}{|c|c|c|c|c|c|c|c|}
\hline \multirow{2}{*}{ Country } & \multicolumn{2}{|c|}{ Census dates } & \multicolumn{3}{|c|}{$\begin{array}{l}\text { Census question(s) on deaths } \\
\text { (Last } 12 \text { months unless indicated otherwise) }\end{array}$} & \multicolumn{2}{|c|}{$\begin{array}{l}\text { Question(s) on pregnancy-related } \\
\text { deaths }\end{array}$} \\
\hline & $\begin{array}{l}\text { First } \\
\text { (MM/YYYY) }\end{array}$ & $\begin{array}{l}\text { Second } \\
\text { (MM/YYYY) }\end{array}$ & Schedule & Location & $\begin{array}{l}\text { Number of } \\
\text { lines }\end{array}$ & $\begin{array}{l}\text { Range of ages of } \\
\text { female deaths }\end{array}$ & Number \\
\hline Burkina Faso $^{1}$ & $12 / 1996$ & $12 / 2006$ & Household & $\begin{array}{l}\text { p. } 3 \text { of } 3 \text { in } \\
1996, \text { p. } 6 \text { of } \\
6 \text { in } 2006\end{array}$ & $\begin{array}{l}7 \text { in } 1996 \\
6 \text { in } 2006\end{array}$ & 10-55 (2006 only) & 3 (2006 only \\
\hline Cambodia & 05/1998 & $03 / 2008$ & Household & p.7 of 7 & 10 & $15-49$ & $1^{2}$ \\
\hline Ethiopia & $10 / 1994$ & $05 / 2007$ & $\begin{array}{l}\text { Household/individual } \\
\text { (long form) }\end{array}$ & p. 3 of 4 & 6 & $12-49$ & 1 \\
\hline Ghana & $03 / 2000$ & $09 / 2010$ & Household/individual & p.11 of 14 & 6 & $12-54$ & $1^{3}$ \\
\hline Liberia & (1984) & $03 / 2008$ & Household/individual & p. 1 of 1 & 4 & $10-49$ & 1 \\
\hline Malawi & 06/1998 & $06 / 2008$ & Household/individual & p. 4 of 4 & 6 & $12-49$ & $3^{3}$ \\
\hline Mozambique & 10/1997 & $08 / 2007$ & Mortality section & & 5 & $12-50$ & 3 \\
\hline Nepal & $06 / 2001$ & $06 / 2011$ & Household/individual & p. 1 of 2 & 2 & $15-49$ & 3 \\
\hline$V$ ietnam ${ }^{4}$ & 04/1999 & $04 / 2009$ & $\begin{array}{l}\text { Mortality information } \\
\text { (long form) }\end{array}$ & p.10 of 12 & 3 & $\begin{array}{l}15-49 \text { excluding } \\
\text { accidental deaths }\end{array}$ & $4^{2,5}$ \\
\hline Zambia & $10 / 2000$ & $10 / 2010$ & Household/individual & p. 4 of 4 & 6 & $12-49$ & $3^{2}$ \\
\hline
\end{tabular}

Note: ${ }^{1}$ Burkina Faso is the only country with both censuses collecting information on household deaths. ${ }^{2}$ Preceded by cause of death question. ${ }^{3}$ Preceded by question(s) as to whether death was due to injury. ${ }^{4}$ Deaths since previous Lunar New Year (approx.. 14 months). ${ }^{5}$ Questions on timing of death relative to pregnancy skipped if due to accident; included explicit category for "after miscarriage/abortion," in addition to "during pregnancy."

The PRPHC emphasize that census data on pregnancy-related deaths needs careful evaluation, possibly with adjustment; such evaluation by standard methods and the calculation of an adjusted PRMR require the collection and compilation of the following pieces of information in addition to deaths by age and sex and whether the deaths were pregnancy-related:

1) Age and sex distribution of the population

2) Births by age of mother for the same clearly defined period before the census

3) Numbers of children ever born to women by age group at the time of the census

A first and critical step in census data processing is editing, whereby invalid or inconsistent data is replaced with plausible values and nonresponses by imputed values. The goal of editing is to ensure an internally consistent data set. Achieving the goal involves assembling a strong editing team comprised of census managers, subject matter specialists, and data processors and following editing best practices, including documentation and archiving of both the unedited and edited data files (UN Department of Economic and Social Affairs 2010; UN Economic Commission for Africa 2015).

Some limited data evaluation can be made if the data comes from only a single census, but the robustness and power of the checks increase if data is available from two successive censuses, ideally separated by no more than 10 to 15 years. All 10 countries included in this review have data from two censuses, an inclusion criterion for the review. For two countries, however, there are question marks over the earlier census 
data: for Liberia, the intercensal interval is 24 years (1984 to 2008), during which interval there was a brutal civil war, and as a result we treat Liberia as if it only had one census, that of 2008; for Nepal, the 2001 census was conducted during a widespread insurgency, and only partial enumeration was possible in 12 out of 75 districts.

The data used in this analysis was either brought to one or other workshop by representatives of the relevant country's national statistical office or were downloaded from the IPUMS web site (Minnesota Population Center 2015).

\section{Methods}

At its most basic, the methodology needed to estimate the PRMR is simple division of the number of pregnancy-related deaths in a period by the number of births in the same period. In practice, in the spirit of the PRPHC paragraph 2.197, the methodology also involves "careful evaluation and often adjustment" of these two numbers. The standard approach to the evaluation of pregnancy-related deaths involves two steps: evaluate (and adjust if necessary) the overall number of female deaths between the ages of 15 (or 10) and 49 and then evaluate the proportion of such deaths reported as pregnancyrelated. It is then necessary to evaluate, and adjust if necessary, the reported number of births. The methods are described in detail elsewhere (WHO 2013; Moultrie et al. 2013), but they will be outlined here with details of how they have been applied.

\subsection{Evaluating numbers of births}

The P/F Ratio approach to evaluating completeness of birth reporting, first proposed by Brass (1975), compares cumulated age-specific fertility rates (ASFRs) to lifetime fertility in the form of average numbers of children ever born (CEB) by age of woman; if reporting is good, and fertility is not changing, the two sets of numbers should be similar. Once again, the details of application depend on data availability (Moultrie et al. 2013); using information from two censuses greatly reduces the sensitivity of the approach to fertility change.

In nine countries, births (from both censuses, except for Cambodia, for which data was only available from the second census) were evaluated by comparison with changes in average numbers of children ever born by age of mother between the first and the second census; thus the estimates are little affected by fertility changes. We treat Liberia as if the only available census was for 2008 , so we applied the methodology to that census only; results would be sensitive to fertility change, but there is no evidence that fertility did change in Liberia given DHS estimates from the 1980s and 2000s. 


\subsection{Evaluating numbers of adult female deaths}

The methods used to evaluate numbers of adult deaths, collectively described as death distribution methods (DDMs), depend on necessary relationships between population numbers, death numbers, and growth rates. How these methods are applied depends on data availability (Moultrie et al. 2013, where spreadsheets for application can be found). There is also an R package to apply the methods (https://cran.r-project.org/packageDDM). In summary, the theory underlying the methods is as follows.

In any population or population age segment that is not significantly affected by migration, the population entry rate minus the population loss (death) rate is equal to the population growth rate. Thus, for example, the rate of entry into the population aged 30 and over (birthdays at age 30 divided by the population aged 30 and over) minus the death rate 30 and over must be equal to the growth rate 30 and over. Differences between entry rates and growth rates, age by age, can be thought of as residual estimates of the death rates over each age; they can then be compared to observed death rates and any systematic differences interpreted as data errors, particularly differences in reporting of deaths relative to reporting of population. These relationships underlie the Brass Growth Balance (BGB) single census method (Brass 1975) and the General Growth Balance (GGB) two census method (Hill 1987). The GGB methodology also provides an estimate of the relative completeness of coverage of two successive censuses.

A second relationship is that the population of a given age today must be equal to all the deaths that will occur to that population in the future; current deaths above that age can be adjusted using age-specific population growth rates to approximate all future deaths. This relationship underlies the Synthetic Extinct Generations (SEG) two census method (Bennett and Horiuchi 1981, 1984). The SEG method primarily estimates completeness of death recording relative to census coverage but can be adapted to allow for differential census coverage.

An evaluation of the performance of these two methods under conditions of simulated data errors suggested that a combination of the two worked better than either method alone (Hill, You, and Choi 2009). The GGB method is applied first to obtain an estimate of differential census coverage; the census counts are then adjusted to correct age-specific growth rates, and the SEG method is applied to the adjusted data.

In application, we note first that, as for fertility, we treat Liberia differently. The two-census evaluation methods are only appropriate for intercensal intervals of 15 years or less, and then only if mortality transitions in the interval have been fairly smooth; for the Liberia case, the intercensal interval was 24 years and was marked by a destructive civil war. Accordingly, for Liberia we apply the original Brass (1975) Growth Balance (BGB) method to the 2008 census data alone, though noting that the Liberian population could not be regarded as truly stable. In all other cases except Burkina Faso, 
the information on deaths by age is available only from the second of the two censuses, so intercensal deaths are estimated by applying reported age-specific mortality rates from the second census to an estimated intercensal population. For Burkina Faso, information on deaths by age is available from both the first and the second census, so age-specific mortality rates were calculated for both censuses, averaged, and then applied to an estimated intercensal population. In each case except Liberia, three evaluation methods were applied: the original GGB method, the original SEG method, and the combined GGB-SEG method, applying the SEG method after adjusting population counts for any census coverage change estimated by the GGB method.

\subsection{Evaluating the proportion pregnancy-related of adult female deaths}

No formal method exists for evaluating a reported proportion of deaths of women of reproductive age that are pregnancy-related. Reported proportions vary widely from population to population and are strongly positively related to the level of maternal mortality. The best option currently available for evaluation is a simple plausibility check: Since pregnancy is the risky event giving rise to pregnancy-related deaths, the age pattern of pregnancy-related deaths should resemble the age pattern of births, with perhaps some flattening of the pattern of pregnancy-related deaths reflecting higher risks at younger and older maternal ages (Blanc et al. 2013).

\subsection{Data adjustment}

Once the formal methods of evaluating completeness have concluded, the question arises of whether to adjust or not. The answer to this question is really a matter of judgment. If the evaluations indicate that errors are small, for example less than $\pm 10 \%$, the decision would normally be not to adjust, since the potential errors in the methods are likely to be at least that large. At the other end of the scale, if the estimated errors are very large, for example, coverage of less than the Preston (Preston 1984) 'rule' of $60 \%$, the assumptions of the methods are probably violated, and the data should probably be abandoned (although the adjustments are at least likely to be in the right direction).

To assist the analyst in applying all the various evaluation methods outlined above, WHO and USAID have supported the development of an Excel workbook (MMEIG 2015) that starts with data inputs in standardized formats and then carries out standard analyses depending on data availability, presenting results with and without adjustment. 
With one or two specified exceptions, the results presented in this paper are derived from the use of the workbook.

\section{Results}

Our primary interest in this paper is not to produce estimates of PRMRs but rather to examine the quality of the census data collected and, to the extent possible, the performance of the evaluation methods used to assess that quality. This section is divided into two parts, the first reviewing results of data evaluation and the second comparing adjusted estimates with those available from other primary sources, principally sibling histories from Demographic and Health Surveys.

\subsection{Data evaluation}

Table 2 summarizes the results of the data evaluation techniques applied to births and adult female deaths by country. The results are expressed in terms of the estimated adjustment factors that need to be applied to the reported numbers; thus a value of 1.23 indicates an upward adjustment of reported numbers of $23 \%$, equivalent to an underreporting of events of $19 \%$.

Table 2: $\quad$ Summary of estimated adjustment factors

\begin{tabular}{llllllll}
\hline \multicolumn{7}{c}{$\begin{array}{l}\text { Adjustment factors } \\
\text { Births }\end{array}$} & \multicolumn{2}{l}{$\begin{array}{l}\text { Female deaths ages } \mathbf{1 5} \text { to } \mathbf{4 9} \\
\text { Country }\end{array}$} & $\mathbf{2 0 - 3 4}$ & \multicolumn{2}{l}{ GGB } & & SEG & & \multicolumn{2}{l}{ GGB/SEG } \\
& & Value & Coeft. of variation* & Value & Coeft. of variation* & Value & Coeft. of variation* \\
\hline Burkina & 1.167 & 1.790 & 0.063 & 2.035 & 0.007 & 2.252 & 0.013 \\
Cambodia & 4.230 & 6.804 & 0.045 & 6.169 & 0.012 & 6.923 & 0.008 \\
Ethiopia & 1.521 & 2.026 & 0.147 & 2.165 & 0.015 & 2.515 & 0.024 \\
Ghana & 1.230 & 1.642 & 0.109 & 1.476 & 0.019 & 2.227 & 0.017 \\
Liberia $^{1}$ & 2.440 & 0.678 & 0.257 & na & na & na & na \\
Malawi & 1.010 & 1.867 & 0.238 & 2.096 & 0.024 & 2.161 & 0.021 \\
Mozambique & 1.348 & 1.800 & 0.096 & 1.656 & 0.017 & 2.091 & 0.024 \\
Nepal & 1.797 & 1.380 & 0.216 & 1.524 & 0.015 & 1.399 & 0.010 \\
Vietnam & 0.980 & 1.562 & 0.026 & 1.814 & 0.004 & 1.757 & 0.003 \\
Zambia & 1.249 & 1.102 & 0.128 & 1.392 & 0.011 & 1.267 & 0.010 \\
\hline
\end{tabular}

Note: *Of adjustment factors using range of age trims (see text). ${ }^{1} 2008$ census only.

The adjustment factor selected from the results of the P/F Ratio method, however implemented, is the average ratio for women aged 20 to 34. The adjustment factors 
range from a low of 0.98 (Vietnam) to a high of 4.23 (Cambodia); the second highest is for Liberia with 2.44. The rule of excluding cases where coverage is estimated at less than $60 \%$ would suggest excluding both Cambodia and Liberia from further analysis; however, since the objective of this paper is methodological rather than substantive, we include both for further discussion.

Turning to adult female deaths, the estimates in Table 2 are based on applying the DDM methods to all open-ended age groups from 5+ to $70+$. An evaluation of the methods by Murray et al. (2010) indicated that method performance varies by the range of age groups ('trims') used and that a narrower age range, from around $50+$ to $70+$ or higher, is generally optimal. However, the advantage of using a smaller number of points for older ages arises largely from limiting the adverse effects on method performance of migration. Since we are applying the methods to national populations, for which net migration rates are typically trivial, we have chosen to use the full range of available points for all applications. We have preferred to use one single age range throughout, since choosing different trims for different applications would add an undesirably arbitrary element to the results.

By way of illustration, Figure 1 shows the GGB, SEG, and GGB-SEG plots for three countries selected on the basis of showing very different coverage adjustments: Vietnam (low), Zambia (medium), and Malawi (high). For Vietnam, the GGB analysis results in a set of points very tightly clustered around a straight line, with only some very slight distortion evident for the points for age groups under $25+$ (nearest the origin); the SEG estimates are close to flat from age 25+ upwards also; the census coverage adjustment increases the estimated death coverage by only about two percentage points. For Zambia, the GGB points cluster quite tightly around a straight line for ages 40 and over, while the SEG points are reasonably consistent for ages 30 and over, but the census coverage adjustment increases the estimated death coverage by a large eight percentage points. For Malawi, the GGB points scarcely approximate a straight line, whereas the SEG points are reasonably consistent for the age range $25+$ to $60+$; despite the jumble of GGB points, the estimated change in census coverage is very small and makes virtually no difference to the SEG death coverage estimates. For both Zambia and Malawi, results may be affected by the fact that the distribution of deaths by age is only available for the second census, and as a result of the waning of the HIV epidemic in both countries, this age pattern may have changed substantially over the decade between the two censuses. One conclusion the plots suggest is that there is no magic age range of points that will always provide robust estimates. 
Figure 1: Performance of death distribution methods: Malawi, Vietnam, and Zambia

\section{GGB}

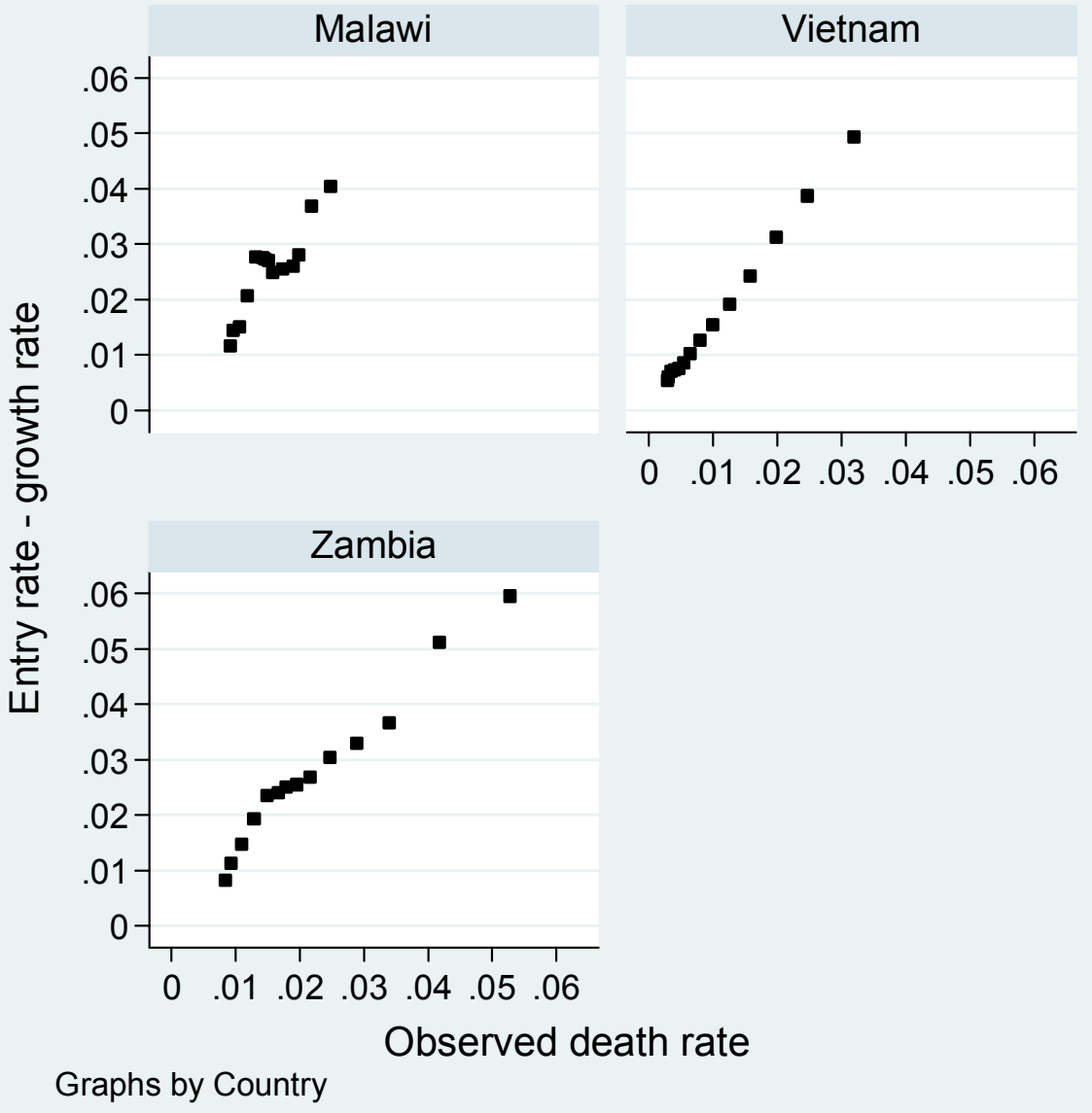


Figure 1: (Continued)

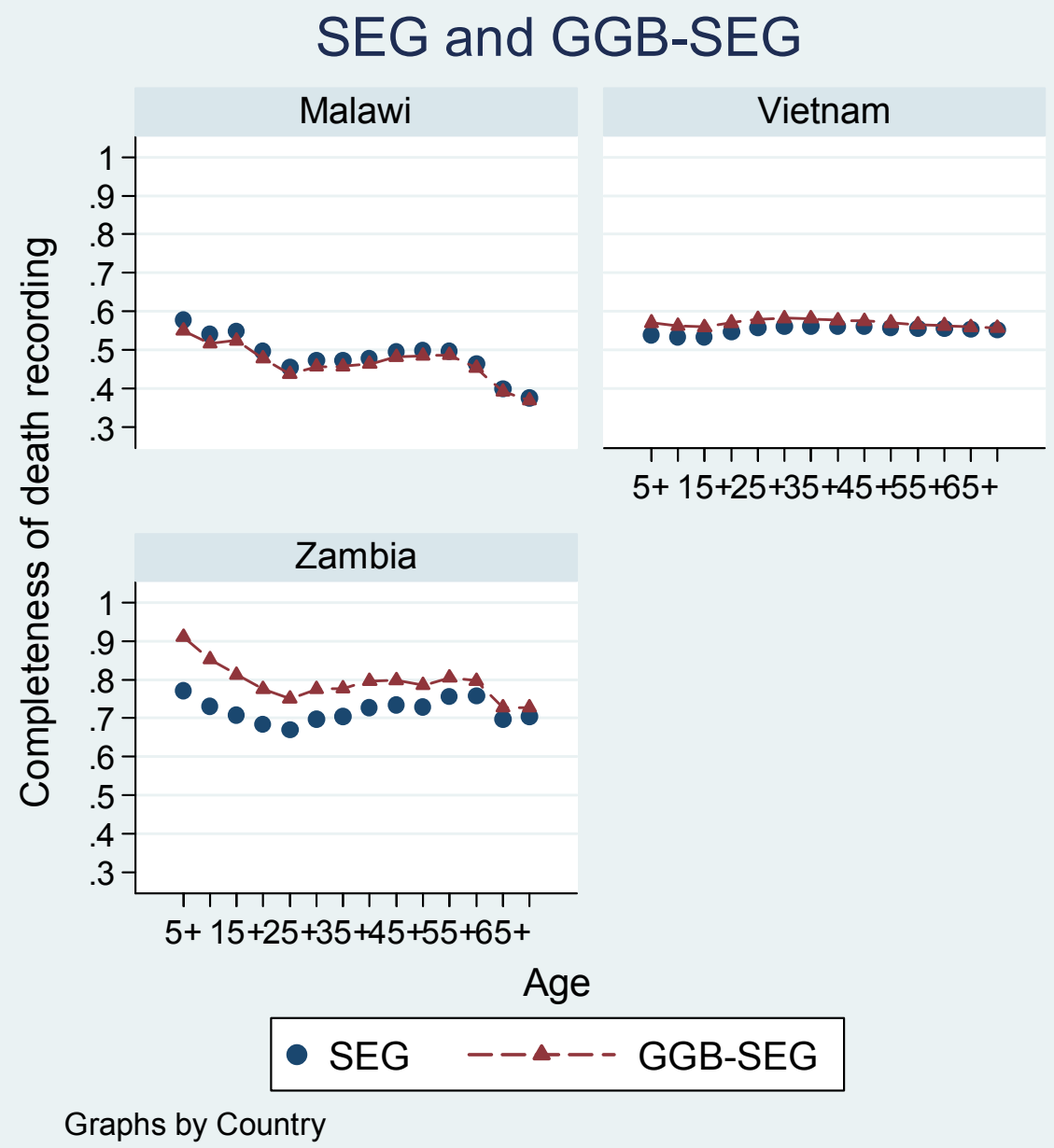

The GGB method uses orthogonal regression to fit a straight line to residual versus observed death rates over each age, whereas the SEG and GGB-SEG methods compare an observed population of a given age to deaths over that age adjusted by age-specific growth rates. The estimates we use are based upon all points for ages $5+$ to $70+$, slope in the case of GGB and average in the case of SEG. There is no established way of 
assessing uncertainty of the results of either approach, but a major component of estimation uncertainty arises from the age ranges used for fitting or averaging. As a broad indicator of uncertainty (Table 2), we have calculated adjustment factors based on a total of 16 different age ranges (5+ to $70+$ down to $20+$ to $55+)$ and calculated the coefficient of variation across the different estimates. It should be noted that this uncertainty measure is not comparable across DDM methods, but within methods it is comparable across countries.

The estimated mortality adjustments tend to be between 1.0 and 2.0 (15 of 28). There is only one adjustment factor less than 1.0 (BGB for Liberia), though there are several larger than 2.0 (12 in total, though 3 of those are for Cambodia, all over 6.0). There is a systematic pattern by method: GGB results in six of the lowest adjustment factors, and the combined method results in six of the highest. We have no explanation of this pattern. The case of Cambodia is of interest: The adjustment factors are all over 6.0, but the indicators of uncertainty are all among the lowest. Given that Cambodia also had a very high adjustment for births, over 4.0, the suspicion is strong that the data used came from a subsample of the 2008 census; the census report gives no indication of this, however, and reports fertility estimates not very different from those we arrive at after adjustment. We conclude from this that the data is usable even though the adjustment factors are very high.

The three evaluation methods applied give three different adjustment factors (except in the case of Liberia, where only the BGB was used) and the differences are not small, ranging from the highest being only $12 \%$ more than the lowest (Cambodia) to being $51 \%$ more than the lowest (Ghana). These differences raise concerns about the usefulness of the methods and a difficult question about what to use as an adjustment factor; for want of a better solution, we use the average of the three estimates, as suggested by Murray et al. (2010). Clearly the uncertainty in the adjustment is large, but there is no plausible case for not adjusting at all.

The third piece of information used in the calculation of a pregnancy-related mortality ratio is the proportion of deaths of women that were pregnancy-related. We have adopted a qualitative test of plausibility. As noted above, we would expect the age pattern of maternal (and pregnancy-related) deaths to resemble the age pattern of fertility but with elevated tails and flattened peak. Inspection of the relative distributions indicates that this is indeed generally the case, though in some cases the difference is more of a rightward shift of the fertility curve (Ghana, Malawi, and Vietnam). In two cases, Liberia and Nepal, there is really no relation between the two patterns, with the proportion of pregnancy-related deaths occurring in each age group declining monotonically from 15-19 to 45-49. This pattern, or lack thereof, raises doubts about the validity of the data from both Liberia and Nepal on proportions of 
deaths that were pregnancy-related. Figure 2 illustrates three different patterns using data from Mozambique, Malawi, and Liberia.

Figure 2: Proportionate distributions of live births and maternal deaths by age of woman: Liberia, Malawi, and Mozambique

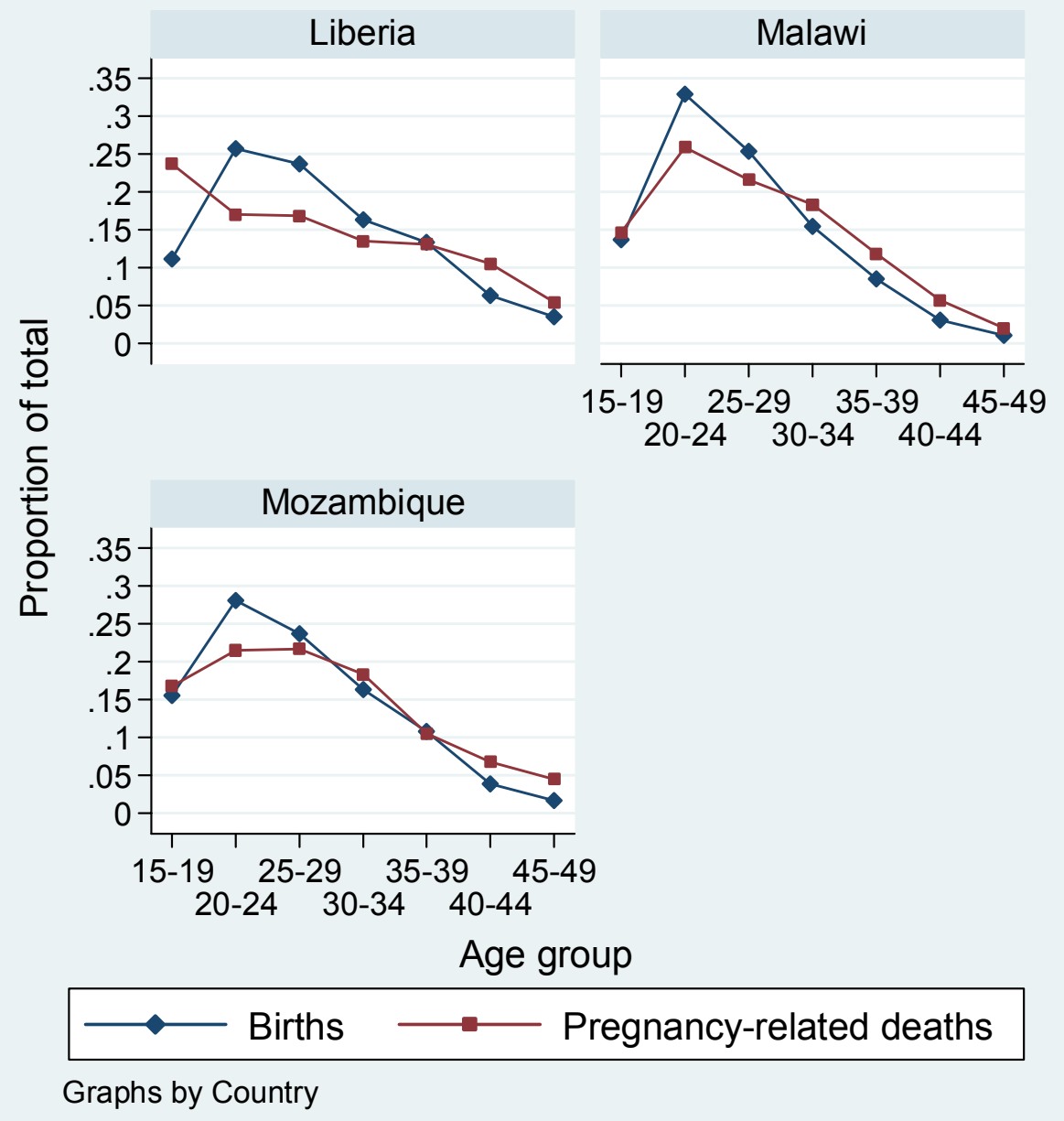




\subsection{Comparing adjusted estimates with those from other sources}

Table 3 compares four indicators (total fertility; the probability of dying between age 15 and age $50\left({ }_{35} \mathrm{q}_{15}\right)$; the proportion of female deaths between ages 15 and 49 pregnancyrelated; and the PRMR) from the census data with estimates of the same indicator from the Demographic and Health Survey of the country that most closely approximates the period covered by each census estimate. The census data has been adjusted as indicated in the previous subsection for all indicators except the proportion of pregnancy-related deaths.

\section{Table 3: Comparisons with DHS Data}

\begin{tabular}{|c|c|c|c|c|c|c|c|c|c|}
\hline \multirow[b]{2}{*}{ Country } & & \multicolumn{2}{|l|}{ TFR } & \multicolumn{2}{|l|}{${ }_{35} q_{15}$} & \multicolumn{2}{|c|}{$\begin{array}{l}\text { Proportion pregnancy- } \\
\text { related }\end{array}$} & \multicolumn{2}{|c|}{$\begin{array}{l}\text { Pregnancy-related } \\
\text { mortality ratio }\end{array}$} \\
\hline & & Census & DHS & Census & DHS & Census & DHS & Census & DHS \\
\hline \multirow{2}{*}{ Burkina } & Period & $1996-2006$ & $2000-2003$ & $1996-2006$ & $2004-2010$ & $1996-2006$ & $2004-2010$ & $1996-2006$ & 2004-2010 \\
\hline & Value & 5.79 & 5.9 & 0.227 & 0.147 & 0.153 & 0.186 & 478 & 341 \\
\hline \multirow{2}{*}{ Cambodia } & Period & 1998-2008 & $2002-2005$ & 1998-2008 & 1999-2005 & 1998-2008 & 1999-2005 & 1998-2008 & 1999-2005 \\
\hline & Value & 3.52 & 3.4 & 0.230 & 0.116 & 0.229 & 0.160 & 1075 & 472 \\
\hline \multirow{2}{*}{ Ethiopia } & Period & 1994-2007 & $1997-2000$ & 1994-2007 & 2005-2011 & 1994-2007 & 2005-2011 & 1994-2007 & 2005-2011 \\
\hline & Value & 6.24 & 5.5 & 0.390 & 0.159 & 0.439 & 0.283 & 2485 & 676 \\
\hline \multirow{2}{*}{ Ghana } & Period & $2000-2010$ & $2005-2008$ & $2000-2010$ & $2002-2007$ & $2000-2010$ & $2002-2007$ & $2000-2010$ & 2002-2007 \\
\hline & Value & 4.48 & 4.0 & 0.269 & 0.137 & 0.023 & 0.141 & 113 & 378 \\
\hline \multirow{2}{*}{ Liberia $^{1}$} & Period & $2007-08$ & 2004-2007 & $2007-08$ & 2001-2007 & $2007-08$ & 2001-2007 & 2007-08 & 2001-2007 \\
\hline & Value & 5.99 & 6.7 & 0.189 & 0.165 & 0.246 & 0.345 & 572 & 994 \\
\hline \multirow{2}{*}{ Malawi } & Period & 1998-2008 & $2001-2004$ & 1998-2008 & 1998-2004 & 1998-2008 & 1998-2004 & 1998-2008 & 1998-2004 \\
\hline & Value & 5.97 & 6.0 & 0.509 & 0.398 & 0.137 & 0.168 & 1338 & 984 \\
\hline \multirow{2}{*}{ Mozambique } & Period & 1997-2007 & 2000-2003 & 1997-2007 & 1997-2003 & $1997-2007$ & 1997-2003 & 1997-2007 & 1997-2003 \\
\hline & Value & 6.74 & 5.5 & 0.520 & 0.194 & 0.121 & 0.187 & 950 & 408 \\
\hline \multirow{2}{*}{ Nepal } & Period & 2001-2011 & 2003-2006 & $2001-2011$ & $2000-2006$ & $2001-2011$ & 2000-2006 & $2001-2011$ & 2000-2006 \\
\hline & Value & 2.84 & 3.1 & 0.082 & 0.081 & 0.224 & 0.197 & 494 & 281 \\
\hline \multirow{2}{*}{ Vietnam } & Period & 1999-2009 & 1999-2002 & 1999-2009 & & 1999-2009 & & 1999-2009 & \\
\hline & Value & 1.95 & 1.9 & 0.048 & NA & 0.031 & NA & 71 & NA \\
\hline \multirow{2}{*}{ Zambia } & Period & 2000-2010 & 2004-2007 & 2000-2010 & 2001-2007 & 2000-2010 & 2001-2007 & 2000-2010 & 2001-2007 \\
\hline & Value & 5.60 & 6.0 & 0.365 & 0.433 & 0.157 & 0.159 & 826 & 591 \\
\hline
\end{tabular}

Note: ${ }^{1} 2008$ census only.

The estimates of total fertility agree fairly closely for 6 of the 10 countries, but for four countries (Ethiopia, Ghana, Liberia, and Mozambique) the census estimate differs from the comparable DHS estimate by more than $10 \%$. In three of these cases, the census estimate is higher and in one lower. The largest difference is for Mozambique, the census estimate being 23\% higher than the corresponding DHS estimate.

Comparisons of mortality indicators are not possible for Vietnam, where no DHSs have included the maternal mortality module. In six of the nine remaining countries, the (adjusted) census estimate of ${ }_{35} \mathrm{q}_{15}$ is at least $25 \%$ higher than the DHS estimate, and in 
two cases (Ethiopia and Mozambique) it is more than double the DHS value. Agreement is very close for one country (Nepal), and the census estimate is about $15 \%$ lower than the DHS estimate for two countries (Liberia and Zambia). Estimates of proportions of pregnancy-related deaths also vary dramatically though not systematically: The census estimates range from 55\% higher (Ethiopia) to more than $80 \%$ lower (Ghana) than the DHS value.

Given the wide differences in female adult mortality and proportions of pregnancy-related deaths, it is hardly surprising that the census and DHS estimates of the PRMR diverge widely. With the exceptions of Ghana ( $70 \%$ lower) and Liberia ( $40 \%$ lower), the census estimates are all higher than the DHS estimates by amounts ranging from $36 \%$ (Malawi) to 268\% (Ethiopia). Ghana is an exception because of an implausibly low proportion in the census of pregnancy-related deaths, while Liberia is an unsatisfactory application of the methodology, since only data from the second census is used.

There is one additional source of information about pregnancy-related mortality relevant to the assessment of census data. The Mozambique 2007 census was followed by a postcensus survey, whereby a sample of deaths reported in the census was followed up by household visits for a verbal autopsy (Mozambique National Institute of Statistics 2012). Of 18,105 deaths in the original sample, over one-third $(6,353)$ were determined to be out of scope mainly because they were determined to have occurred outside the 12 month reference period. The remaining in-scope deaths do not provide a suitable basis for estimating mortality rates because the procedure used provides no way of adjusting for deaths that were not originally reported to the census but should have been; false positives are identified but not false negatives (Hakkert 2011). That said, it may be that the remaining sample was not biased by cause. Maternal deaths as identified by the verbal autopsy were $14 \%$ of deaths of women of reproductive age, and maternal deaths were $96 \%$ of pregnancy-related deaths. The proportion of deaths of women of reproductive age that were pregnancy-related was thus about $15 \%$, somewhat higher than the value calculated from the overall census data. It is worth noting the close similarity in the Mozambique case between the number of maternal deaths and the number of pregnancy-related deaths, suggesting that pregnancy-related deaths can be a reasonably good proxy for maternal deaths in contexts where maternal mortality is high.

\section{Discussion}

For over 25 years, maternal mortality has been a key indicator of population health. However, in the absence of a fully functional CRVS system, it has proved very hard to measure satisfactorily. The sisterhood method, widely applied in DHS and more 
recently in MICS surveys, gives estimates with large potential sampling errors and the possibility of systematic errors as well; it does not lend itself to disaggregation, whether by geography or socioeconomic condition. An alternative, cautiously promoted by the second revision of the PRPHC, is to include questions in censuses on household deaths and - for female deaths of reproductive age - follow-up questions about the timing of death relative to pregnancy. This approach offers the possibility of much larger samples, and of disaggregation, but data quality remains an issue. In this paper we update earlier evaluations (Stanton et al. 2001; Hill et al. 2007, 2009; Hill and Stanton 2011), incorporating data from the 2010 round of censuses to evaluate data quality across a number of recent census data sets.

The evaluation methods applied to the census data make a number of assumptions that may affect the results. The $\mathrm{P} / \mathrm{F}$ Ratio method applied to a single data set is very sensitive to fertility change, but in only one application, Liberia, is the single data set method used; in all others, data from two successive censuses is used. The method whether applied to a single census or to a pair of censuses - in principle also assumes zero migration, but in practice the results are little affected by levels of migration likely to be observed at the national level.

The death distribution methods make stronger assumptions. As applied here for eight countries (Burkina Faso, with age patterns of mortality from both censuses, and Liberia, which is treated as only having a single census, are the exceptions), with information on deaths available only from the second census, it is assumed that the age pattern of mortality rates observed at the second census applied throughout the intercensal period; in countries affected by the HIV epidemic, that is an unrealistic assumption, but apart from affecting goodness of fit, there is no clear direction that any bias would take. It is further assumed that completeness of reporting of deaths does not vary with age; results are sensitive to this assumption, such that if reporting improves with age the adjustment factors will be biased downwards, and vice versa (Hill, You, and Choi 2009). In practice, we have little idea how completeness of reporting varies with age, though Dorrington and Bradshaw (2011) argue that in the case of South Africa, deaths may be overreported at younger ages (because of possible reporting by multiple households) and underreported at older ages (as a result of household dissolution). Finally, the methods assume no net migration. At the national level, this assumption is often reasonable, but net emigration during the intercensal period will (counterintuitively) tend to bias GGB and GGB-SEG adjustment factors downwards while biasing SEG estimates upwards and vice versa for immigration (Hill, You, and Choi 2009); one clear consequence of migration is that GGB and SEG estimates will diverge with biases in different directions, so averaging results of the methods will reduce bias. For Liberia, we have to assume additionally that the population is approximately demographically stable. 
It is not possible to put formal confidence intervals on the fertility or mortality estimates derived from the censuses considered in this paper. It is however clear that there is a great deal of uncertainty. With the GGB mortality estimates, for example, the coefficient of variation from using different age ranges for fitting varies from $2.6 \%$ (Vietnam) to $25.7 \%$ (Liberia); the SEG or combined method variability is much lower, but this is misleading since there is added uncertainty with these two methods about the treatment of the 'open' age interval. There is additional uncertainty in the fertility adjustments and in the proportions of adult female deaths that are pregnancy related.

What conclusions can we draw from these applications? First, the most robust evaluation methodology that we use is of fertility, and reported fertility almost always needs to be adjusted upward from reported levels. Comparisons of adjusted total fertility rates with empirical estimates for broadly comparable time periods from DHS suggest no net bias: For five applications, the estimates are very similar, for three the census estimates are higher, and for two the census estimates are lower.

Second, even though there is substantial uncertainty in the adjustment factors produced, the results of the evaluations of adult female mortality indicate the need for upward adjustment in all cases except one, the exception being the unsatisfactory application to Liberia. Hill, You, and Choi (2009) show that the largest distortions of estimates of adjustment factors arise from net migration and from age-specific patterns of underreporting of age at death. United Nations estimates of net migration for the period 2000-2010 (UN Department of Economic and Social Affairs 2017) for seven of the countries included in this study indicate rates per 1,000 below 2 per 1,000, unlikely to have a major impact on coverage estimates; only Cambodia (-2.4), Nepal (-7.1), and Liberia $(+3.2)$ have rates higher than that. Unfortunately, we have little information about even the direction of age-specific patterns of misreporting of deaths beyond the South Africa case (Dorrington and Bradshaw 2011), which is unlikely to be typical. Comparisons of an overall indicator of adult female mortality, ${ }_{35} \mathrm{q}_{15}$, between the adjusted census values (averaging adjustment factors across the three approaches) and the only other source of empirical information, DHS sisterhood reports, show the adjusted census estimates to be substantially higher in all but two cases. The adjustment methods have large uncertainty, but since migration bias is likely to be downward in most of these applications, this systematic pattern raises the possibility that the DHS sisterhood method underestimates adult mortality substantially.

The census estimates and DHS estimates of the proportion of pregnancy-related deaths (PPRD) in some cases differ by large amounts but do not appear to differ systematically. For four countries the census proportion is lower than the DHS proportion (by amounts ranging from $18 \%$ to $35 \%$ ), for three higher (by amounts ranging from $14 \%$ to $55 \%$ ), and for one country agreement is very close. There is one country, however, for which the PPRD is implausibly low: Ghana, with a value of only 
$2.3 \%$, has a lower proportion even than low-fertility low-mortality Vietnam; a 2007 DHS in Ghana found a proportion of nearly $16 \%$ (Ghana Statistical Service et al. 2009). The Ghana census questionnaire offers no obvious reason for why the PPRD should be so low: The question on timing of death was preceded by a question on whether the death was due to an accident or violence, but that was also the case for Malawi; the question was integrated appropriately with the other questions on deaths in the household. Dorrington and Bradshaw (2011) conclude in their analysis of South African census data that the proportion of adult female deaths reported as pregnancyrelated was overreported; our analysis does not suggest that this is the norm, unless the same is true of DHS sibling data.

Reviewing more generally the evaluation results in the context of questionnaire design, it is hard to see any general patterns. In almost all the censuses, the questions on recent household deaths were close to the end of quite long questionnaires (see Table 1 for a summary and web appendix for facsimiles), so it could be that interviewer fatigue played a role in the underrecording of recent deaths. However, in Nepal the question was upfront, and yet coverage is estimated to have been about average. In most cases, the census questionnaire allowed for five or six deaths in a household; without household-level data, it is impossible to know whether the number of lines curtailed the number of deaths reported, but it seems very unlikely that many households experienced more deaths than that in a year. Nepal, however, had lines for only two deaths per household, with no instruction on the questionnaire about what to do if more were recorded, so the design of the questionnaire may have reduced data quality.

The Global Burden of Disease (GBD) and MMEIG studies have been making estimates of maternal mortality by country and time period for over a decade. As a final point of comparison, Table 4 compares the PRMR from Table 3 with the MMEIG (WHO 2015) and GBD (Global Burden of Disease Collaborative Network 2016) point estimates of MMR; both the MMEIG and the GBD present estimates for five-year time points from 1990 to 2015; we have selected the estimates for 2005 as being closest to the time reference of the census-based estimates. The first thing to notice is that the MMEIG estimates are uniformly higher than the GBD estimates; since the adjusted census estimates are generally higher still (the only exceptions are Ghana and Liberia, both special cases), we will initially compare these estimates to the MMEIG estimates. The adjusted census estimates are within $25 \%$ of the MMEIG estimates for four countries (Burkina Faso, Nepal, Vietnam, and Mozambique), well below the point estimates for two countries (Ghana and Liberia) and well above for four countries (in two cases by a factor of over 3 ). The adjusted census estimates are clearly closer to the MMEIG estimates than the unadjusted estimates for three countries (Burkina Faso, Nepal, and Vietnam) and clearly farther from them for four countries (Cambodia, Ethiopia, Malawi, and Mozambique). Discrepancies with GBD estimates would in most 
cases be even larger. It must be remembered of course in these comparisons that the census estimates are of pregnancy-related mortality, which in low-mortality countries (here represented by Vietnam) may substantially exceed maternal mortality.

Table 4: Comparison of census-based estimates of PRMR with MMEIG and GBD estimates of MMR for 2005

\begin{tabular}{llcccc}
\hline Country & $\begin{array}{l}\text { Census estimate of PRMR } \\
\text { Time period }\end{array}$ & Unadjusted & Adjusted & $\begin{array}{c}\text { MMEIG estimate } \\
\text { of MMR }\end{array}$ & $\begin{array}{c}\text { GBD estimate } \\
\text { of MMR }\end{array}$ \\
\hline Burkina & $1996-2006$ & 278 & 478 & 468 & 372 \\
Cambodia & $1998-2008$ & 961 & 1075 & 315 & 286 \\
Ethiopia & $1994-2007$ & 1,739 & 2,485 & 743 & 665 \\
Ghana & $2000-2010$ & 79 & 113 & 376 & 225 \\
Liberia $^{1}$ & $2007-2008$ & 1,929 & 572 & 1,020 & 653 \\
Malawi & $1998-2008$ & 808 & 1,338 & 648 & 387 \\
Mozambique & $1997-2007$ & 703 & 950 & 762 & 291 \\
Nepal & $2001-2011$ & 625 & 494 & 444 & 373 \\
Vietnam & $1999-2009$ & 41 & 71 & 61 & 29 \\
Zambia & $2000-2010$ & 823 & 826 & 372 & 366 \\
\hline
\end{tabular}

Note: ${ }^{1} 2008$ census only.

What can we make of this comparison? Is the adjustment process making things worse rather than better? It is worth pointing out that the MMEIG and GBD estimates are just that, estimates (and the GBD estimates do look surprisingly low, notably in the case of Mozambique). We have reasonable confidence in the methodology used to adjust numbers of births, so if the adjusted census estimates of PRMR are too high, the problem must be either adjusting the recorded number of deaths up too much or overrecording the proportion of pregnancy-related deaths. There is no clear pattern in the comparison of pregnancy-related proportions in the censuses versus DHSs (Table 3): The census proportions are higher in three cases, lower in five cases, and almost identical in one case. If the census pregnancy-related proportions are not systematically biased but the adjusted estimates are too high, the adjustment of deaths must be systematically too high. Though there may be country-specific reasons why the adjustment of deaths may be too high (immigration or decreasing completeness of reporting of deaths with age, for example), a uniform upward bias in DDM adjustments seems unlikely, raising questions about the accuracy of the MMEIG and GBD estimates. 


\section{Conclusion}

As stated in the introduction, the purpose of this paper is not to add more estimates of maternal mortality to existing databases but rather to evaluate the usefulness of census data in the measurement of maternal mortality. The review has focused on the plausibility of the basic data collected by recent censuses as they relate to maternal mortality and on the performance of the adjustment techniques applied to census data on fertility and adult mortality. It updates previous evaluations incorporating data from the 2010 round of censuses.

Our results basically reinforce the conclusions of the earlier evaluations; disappointingly there has been no clear improvement in data quality. We conclude that the census data on fertility generally somewhat underreport recent births but except in the cases of Cambodia and Liberia are not far wrong. For mortality, the data appears to underreport recent adult female deaths by a larger margin. Conclusions with respect to the proportion pregnancy-related of adult female deaths are weaker but suggest no clear bias.

With respect to assessment and adjustment methods, we conclude that the fertility adjustments usually work quite well and improve on the reported data. For mortality, the general direction of adjustment seems likely to be correct, but there is so much uncertainty around a precise adjustment factor that any final adjustment is little better than a guess; wider application to cases with data on deaths by age from both censuses may improve performance. For pregnancy-related proportions, the evaluation through age patterns of deaths is only qualitative; development of a quantitative approach potentially allowing for adjustment is desirable.

Our overall conclusion about the use of census questions to estimate maternal mortality is similar to that of the UN Principles and Recommendations for Population and Housing Censuses and similar to those of earlier reviews. The majority of the uncertainty surrounding census-based estimates of pregnancy-related mortality arises from uncertainty about numbers of adult female deaths; the question of whether to include questions related to maternal mortality in a census boils down to the question of whether to include questions on recent household deaths in the census. To answer this question requires a systematic analysis of all such data, whether in the context of maternal mortality or in the broader context of overall mortality. In countries lacking adequate CRVS systems, there is so little information on adult mortality that the inclusion of questions on household deaths by age and gender in the year before the census is justified, in part because census information on household deaths also feeds into the estimation of child and adolescent mortality. Availability of census data on deaths by age from both first and second censuses is also valuable, since it permits allowance for changes in the age pattern of mortality; additional data from the 2020 
round of censuses may therefore be expected to improve the performance of the DDM evaluation methods. If questions on household deaths are being included, additional questions about the timing of death relative to pregnancy can be included with little additional workload relative to that of conducting a census; this study does not determine whether a one question or three question format is preferable, but the three question approach provides more information and potentially an additional basis for evaluation.

\section{Funding statement}

This study was carried out with support provided by the United States Agency for International Development (USAID) through MEASURE Evaluation (cooperative agreement AID-OAA-L-14-00004). The views expressed are those of the authors and do not necessarily reflect the views of the United States Agency for International Development (USAID) or the United States Government.

\section{Acknowledgements}

We are grateful to the Carolina Population Center and its NIH Center grant (P2C HD050924) for general support. 


\section{References}

Ahmed, S., Li, Q., Scrafford, C., and Pullum, T.W. (2014). An assessment of DHS maternal mortality data and estimates. Rockville: ICF International (DHS Methodological Reports No. 13).

Banda, R., Fylkesnes, K., and Sandøy, I.F. (2015). Rural-urban differentials in pregnancy-related mortality in Zambia: Estimates using data collected in a census. Population Health Metrics 13(1): 32. doi:10.1186/s12963-015-0066-9.

Banda, R., Sandøy, I.F., and Fylkesns, K. (2016). Lifetime risk of pregnancy-related death among Zambian women: District-level estimates from the 2010 census. Journal of Population Research 33(3): 263-281. doi:10.1007/s12546-0169172-1.

Bennett, N.G. and Horiuchi, S. (1981). Estimating the completeness of death registration in a closed population. Population Index 47(2): 207-221. doi: $10.2307 / 2736447$.

Bennett, N.G. and Horiuchi, S. (1984). Mortality estimation from registered deaths in less developed countries. Demography 21(2): 217-233. doi:10.2307/2061041.

Blanc, A.K., Winfrey, W., and Ross, J. (2013). New findings for maternal mortality age patterns: Aggregated results for 38 countries. PLoS ONE 8(4): e59864. doi:10.1371/journal.pone. 0059864 .

Brass, W. (1975). Methods for estimating fertility and mortality from limited and defective data. Chapel Hill: International Program of Laboratories for Population Statistics.

Dorrington, R.E. and Bradshaw, D. (2011). Maternal mortality in South Africa: Lessons from a case study in the use of deaths reported by households in censuses and surveys. Journal of Population Research 28(1): 49-73. doi:10.1007/s12546-0119050-9.

Ghana Statistical Service (GSS), Ghana Health Service (GHS), and Macro International (2009). Ghana Maternal Health Survey 2007. Calverton: GSS, GHS, and Macro International.

Global Burden of Disease Collaborative Network (2016). Global Burden of Disease Study 2016 (GBD 2016) results [electronic resource]. Seattle: Institute for Health Metrics and Evaluation. http://ghdx.healthdata.org/gbd-results-tool. 
Hakkert, R. (2011). Follow-up surveys for census estimates of maternal mortality: Experiences from Bolivia and Mozambique. Journal of Population Research 28(1): 15-30. doi:10.1007/s12546-011-9063-4.

Hill, K. (1987). Estimating census and death registration completeness. Asian and Pacific Census Forum 1(3): 8-13, 23-24.

Hill, K. (2013). Estimation of pregnancy-related mortality from deaths reported by households. In: Moultrie, T.D., Dorrington, R., Hill, A., Hill, K., Timæus, I.M., and Zaba, B. (eds.). Tools for demographic estimation. Paris: International Union for the Scientific Study of Population.

Hill, K., Stanton, C., and Gupta, N. (2001). Measuring maternal mortality from a census: Guidelines for potential users. Chapel Hill: Carolina Population Center, University of North Carolina.

Hill, K., Queiroz, B., Stanton, C., and Abou-Zahr, C. (2007). Measuring maternal mortality via the population census: Experience from Africa. Paper presented at the $5^{\text {th }}$ African Population Conference, Arusha, Tanzania, December 10-14, 2007.

Hill, K., Queiroz, B.L., Wong, L., Plata, J., Del Popolo, F., Rosalese, J., and Stanton, C. (2009). Estimating pregnancy-related mortality from census data: Experience in Latin America. Bulletin of the World Health Organization 87(4): 288-295. doi:10.2471/BLT.08.052233.

Hill, K., You, D., and Choi, Y. (2009). Death distribution methods for estimating adult mortality: Sensitivity analysis with simulated data errors. Demographic Research 21(9): 235-254. doi:10.4054/DemRes.2009.21.9.

Hill, K. and Stanton, C. (2011). Measuring maternal mortality through the census: Rapier or bludgeon? Journal of Population Research 28(1): 31-47. doi:10.1007/ s12546-011-9058-1.

Maternal Mortality Inter-Agency Group (MMIEG) Census Technical Working Group (2015). Census pregnancy-related mortality workbook: Version 2.0R [electronic resource].

Kish, L. (2003). Methods for design effects. In: Kalton, G. and Heeringa, S. (eds.). Leslie Kish: Selected papers. Hoboken: Wiley: 155-178.

Masquelier, B. (2013). Adult mortality from sibling survival data: A reappraisal of selection biases. Demography 50(1): 207-228. doi:10.1007/s13524-012-0149-1. 
Minnesota Population Center (2015). Integrated public use microdata series, international: Version 6.4 [machine-readable database]. Minneapolis: University of Minnesota.

Moultrie, T.A., Dorrington, R.E., Hill, A.G., Hill, K., Timæus, I.M., and Zaba, B. (2013). Tools for demographic estimation. Paris: International Union for the Scientific Study of Population.

Mozambique National Institute of Statistics, US Census Bureau, MEASURE Evaluation, and US Centers for Disease Control and Prevention (2012). Mortality in Mozambique: Results from a 2006-2007 post-census mortality survey. Chapel Hill: Measure Evaluation.

Murray, C.J.L., Rajaratnam, J.K., Marcus, J., Lasko, T., and Lopez, A.D. (2010). What can we conclude from death registration? Improved methods for evaluating completeness. PLoS Med 7(4): e1000262. doi:10.1371/journal.pmed.1000262.

Preston, S.H. (1984). Use of direct and indirect techniques for estimating the completeness of death registration systems. In: Data bases for mortality measurement. New York: United Nations.

Queiroz, B.L. (2011). Estimating maternal mortality differentials using census data: Experience in Honduras. Journal of Population Research 28(1): 75-87. doi:10.1007/s12546-011-9044-7.

Rutenberg, N. and Sullivan, J.M. (1991). Direct and indirect estimates of maternal mortality from the sisterhood method. Washington, D.C.: IRD/Macro International.

Stanton, C., Hobcraft, J., Hill, K., Kodjogbe, N., Mapeta, W.T., Munene, F., Naghavi, M., Rabeza, V., Sisouphanthong, B., and Campbell, O. (2001). Every death counts: Measurement of maternal mortality via a census. Bulletin of the World Health Organization 79(7): 657-664.

United Nations (2007). Principles and recommendations for population and housing censuses. New York: United Nations, Statistics Division, Department of Economic and Social Affairs.

United Nations (2015). Transforming our world: The 2030 Agenda for Sustainable Development 2015: Resolution adopted by the General Assembly on 25 September 2015: United Nations General Assembly, seventieth session, A/RES/70/1. http://www.un.org/ga/search/view_doc.asp?symbol=A/RES/70/1. 
United Nations Department of Economic and Social Affairs, Population Division (2017). World population prospects: The 2017 revision: DVD edition.

United Nations Economic Commission for Africa (2015). Africa census editing handbook. Addis Abeba: UNECA.

United Nations Department of Economic and Social Affairs, Statistics Division (2010). Handbook on population and housing census editing: 1st revision. New York: United Nations.

World Health Organization (WHO) (1993). International statistical classification of diseases and related health problems: 10th revision. Geneva: WHO.

World Health Organization (WHO) (2007). Verbal autopsy standards: Ascertaining and attributing causes of death. Geneva: WHO.

World Health Organization (WHO) (2013). WHO guidance for measuring maternal mortality from a census. Geneva: WHO. http://apps.who.int/iris/bitstream/ 10665/87982/1/9789241506113_eng.pdf.

World Health Organization (WHO) (2015). Trends in maternal mortality: 1990 to 2015: Estimates by WHO, UNICEF, UNFPA, World Bank Group and the United Nations Population Division. Geneva: WHO. 
Hill et al:: Using census data to measure maternal mortality: A review of recent experience 